\title{
Editorial
}

\section{LANDFILLING OR BIKING?}

The first day of the Solid Waste Management course I teach at the University of Padua, Italy, I usually ask the students a simple question:

"In your opinion, which is the best system of waste management?"

Their immediate reply, in chorus and with very few exceptions, is: "Recycling!"

I then go on to the second question.

"In your opinion, which is the best means of transport?"

After a moment of bewilderment due to this abrupt jump from one topic to another, no response is forthcoming until the first brave person breaks the ice: "It depends!" I ask for an explanation and immediately receive a clear, logical justification. Everyone agrees that it is reasonable to think that to go from Paris to Beijing by car or by train may be nostalgically romantic, or at least adventurous, but it is much more practical to fly there. On the contrary, it would, to say the least, be totally absurd, or even grotesque, to think of catching a plane to go to buy the bread!

We further developed the discussion by mentioning how, for reasons of practicality, we rarely use the same means of transport all the time. We walk to the garage to get the car. We use the car to get to the airport. Here we board a plane and, on leaving the plane we may indeed catch a train or take a boat, or ....

I then ask my third question:

"Why do you reply «it depends» when referring to means of transport, taking into account your requirements at the time and the context in which you are placed, whilst giving such a decisive answer when focusing on waste management?"

I then go on to ask a fourth question: "Why did it not occur to you to combine the different methods of waste treatment and disposal?" Indeed, in the same way that means of transport are largely diverse, the field of waste management affords a series of well-differentiated options, as follows:

minimization of waste generation;

- recovery and recirculation of material resources present in the wastes;

- combustion of waste with the main aim of reducing waste volumes;

- landfilling of residual wastes in order to close the material loop.

Of course, these diverse options are applied using different and increasing levels of technology, advanced and not so advanced, sophisticated or less sophisticated, ef- ficient and less efficient, both reliable and less reliable. It is however undeniable that, in the same way as transportation, and particularly in view of the knowledge we possess, these solutions must be combined and integrated. On analyzing the disposal techniques adopted worldwide, it is clear that countries characterized by a high population density (e.g. Japan, Singapore, Denmark, Germany, etc.) benefit enormously from the use of incineration combined with intense programs for the recovery of material resources (sorting, recycling, biological treatment) and with landfilling of residual wastes (Cossu, 2009). At the same time, countries with a low population density prefer to combine waste recycling with landfilling (e.g. Canada, United States, etc.).

Why then do my students fail to implement the obvious concepts that we rationally apply to the transportation of people and goods to the systems of waste management?

The response obtained from my students is indeed aligned with the response of the majority of the population (Figure 1): "because incinerators and landfills pollute the environment and endanger our health!".

We are well aware that all waste management technologies, ranging from composting to landfill, and from mechanical treatment to incineration, are characterized by the emission of contaminants that should be, wherever possible, prevented and rigorously monitored. Even the recovery and recirculation of waste materials results in the accumulation of a series of contaminants contained in the materials, and are certainly not devoid of negative environmental impacts.

However, on taking a closer look, the various means of transport do not fare too well in the field of emission of contaminants and environmental risks.

Over recent decades the use of planes has risen exponentially thanks to the diffusion of low-cost airlines, but this form of transport is characterized by high emissions of noise, greenhouse gases, $\left(\mathrm{NO}_{\mathrm{x}}\right.$ and $\left.\mathrm{CO}_{2}\right)$, and risks linked to cosmic radiations.

Maritime transport likewise produces both atmospheric pollution through the emission of carbon dioxide, sulfur dioxide, nitrogen oxides and particulate due to the use of poorly refined fuel oils, and water pollution through leakages of oils, solid wastes and liquids. An increase in the number of cruise ships may indeed upset the equilibrium in delicate and sensitive ecosystems (Artic, Antarctic, coral reefs, lagoons, etc.).

Even trains, the means of transport operationally linked to production of the lowest amounts of greenhouse gases, 


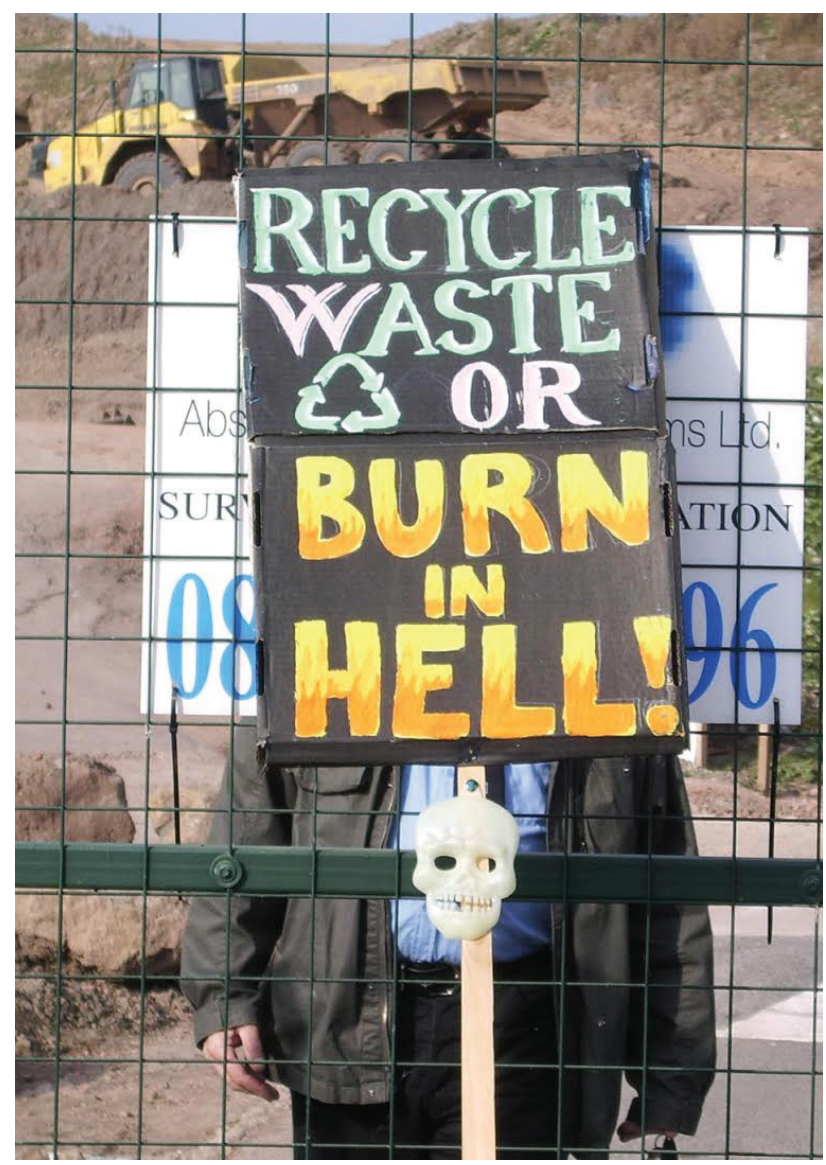

FIGURE 1: An example of the reaction of the population to waste management issues. (Courtesy of Vertigogen, from Flickr).

on taking into account all the infrastructures associated with operations (tracks, stations, etc.), prove to be even less competitive than planes in a detailed life cycle analysis (Chester and Horvat, 2009). There is little point in referring to cars, being the most highly targeted method of transport from both an environmental and political viewpoint.

On considering the risks involved, a particularly alarming situation is manifested for all methods of transport. Unfortunately, planes at times may crash, ships may sink, trains may derail and road accidents destroy cars, bicycles and pedestrians ....
Of course the available technologies are in a position to strongly attenuate the pollution and risks lined to means of transport, but the same is true also for waste management systems.

Why therefore do my students, and the public opinion in general, provide such different answers?

It is because methods of transport are not bombarded by defamatory campaigns comprising aggressive misinformation and by political manipulation which, on the contrary, have massively impinged on the field of waste management on a communicative and regulatory level.

It is easy to find how landfilling and incineration, without any evidence or scientific documentation, have been associated to cancer (gastrointestinal, esophageal, lung, stomach, colon, rectal ...), birth defects and reproductive disorders (low birth weight, fetal and infant mortality, spontaneous abortion, malformations...) and other problems (cardiovascular diseases, respiratory symptoms, asthma, reduced lung function, irritation of the skin, nose and eyes, gastrointestinal problems, fatigue, headaches, psychological problems, allergies ...).

This fake news has created dangerous prejudices and scaremongering that has given rise to paradoxical solutions and diseconomies. The example of several Italian cities where waste management has been rather improperly associated with the systems of transportation is well known! Indeed, numerous wastes produced in cities where the local administrations had rejected incineration and landfills in favor of recycling, have actually been loaded onto trains, ships and lorries to be disposed of abroad, after a long journey. How? By means of incineration and landfilling!

Hurrah! Let's get ready to go biking to Beijing!!!

Raffaello Cossu University of Padova, Italy raffaello.cossu@unipd.it

\section{REFERENCES}

Cossu R. (2009) ). Driving forces in national waste management strategies. Waste Management 29, 2797-2798

Chester M.V.and Horvath A. (2009). Environmental assessment of passenger transportation should include infrastructure and supply chains. Environmental Research Letters 4, 024008. 